Portland State University

PDXScholar

2-10-1993

\title{
An Analysis of Conceptual Metaphor in Marital Conflict
}

Anne Elizabeth Burgermeister-Seger

Portland State University

Follow this and additional works at: https://pdxscholar.library.pdx.edu/open_access_etds

Part of the Speech and Rhetorical Studies Commons

Let us know how access to this document benefits you.

\section{Recommended Citation}

Burgermeister-Seger, Anne Elizabeth, "An Analysis of Conceptual Metaphor in Marital Conflict" (1993). Dissertations and Theses. Paper 4528.

https://doi.org/10.15760/etd.6412

This Thesis is brought to you for free and open access. It has been accepted for inclusion in Dissertations and Theses by an authorized administrator of PDXScholar. Please contact us if we can make this document more accessible: pdxscholar@pdx.edu. 
AN ABSTRACT OF THE THESIS OF Anne Elizabeth Burgermeister-Seger for the Master of Science in Speech Communication presented February 10, 1993. Title: An Analysis of Conceptual Metaphor in Marital Conflict APPROVED BY THE MEMBERS OF THE THESIS COMMITTEE:

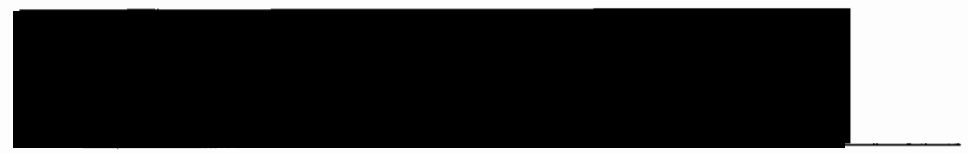

Peter C. Ehrenhaus, Chair

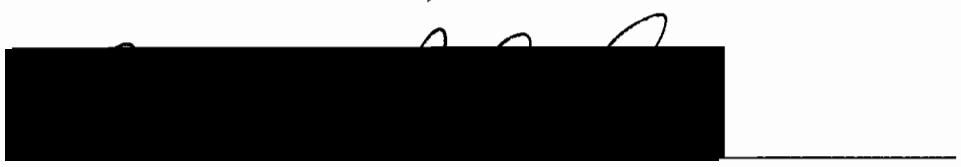

David Ritchie

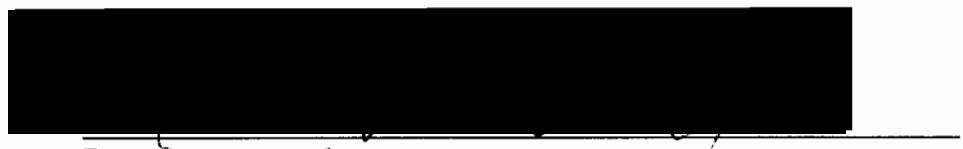

Larry Steward

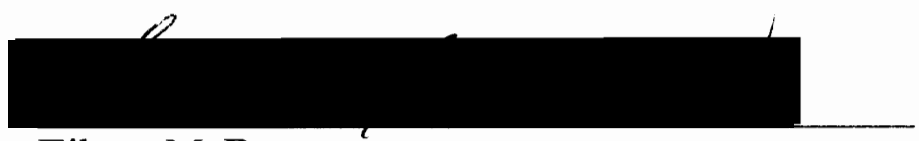

Eileen M. Brennan

This thesis investigates metaphoric structure revealed during discussions about conflict, and poses the general question: What conceptual metaphors do married individuals use to structure their marital conflict?

Theoretical issues of metaphor analysis and general issues of conflict management are reviewed, providing a background for the study's approach to data collection and analysis. Eight married individuals were interviewed. Interviews were tape recorded. The interview schedule was structured around issues of topic, setting, process, response, and communication of typical, as well as a most recent, 
marital conflict. More specific probing followed respondents' comments. Using techniques of interpretive analysis, transcripts from the interviews were analyzed for emergent metaphors. Data from the transcripts coalesced around the topics of structural, ontological, and orientational metaphors.

Implications for conflict management and marital counseling are discussed. Finally, in view of the study's limitations and strengths, the thesis concludes with suggested directions for future research. 
AN ANALYSIS OF CONCEPTUAL METAPHOR IN MARITAL CONFLICT

by

ANNE ELIZABETH BURGERMEISTER-SEGER

A thesis submitted in partial fulfillment of the requirements for the degree of

\section{MASTER OF SCIENCE \\ in \\ SPEECH COMMUNICATION}

Portland State University

1993 


\section{TO THE OFFICE OF GRADUATE STUDIES:}

The members of the Committee approve the thesis of Anne Elizabeth Burgermeister-Seger presented February 10, 1993.

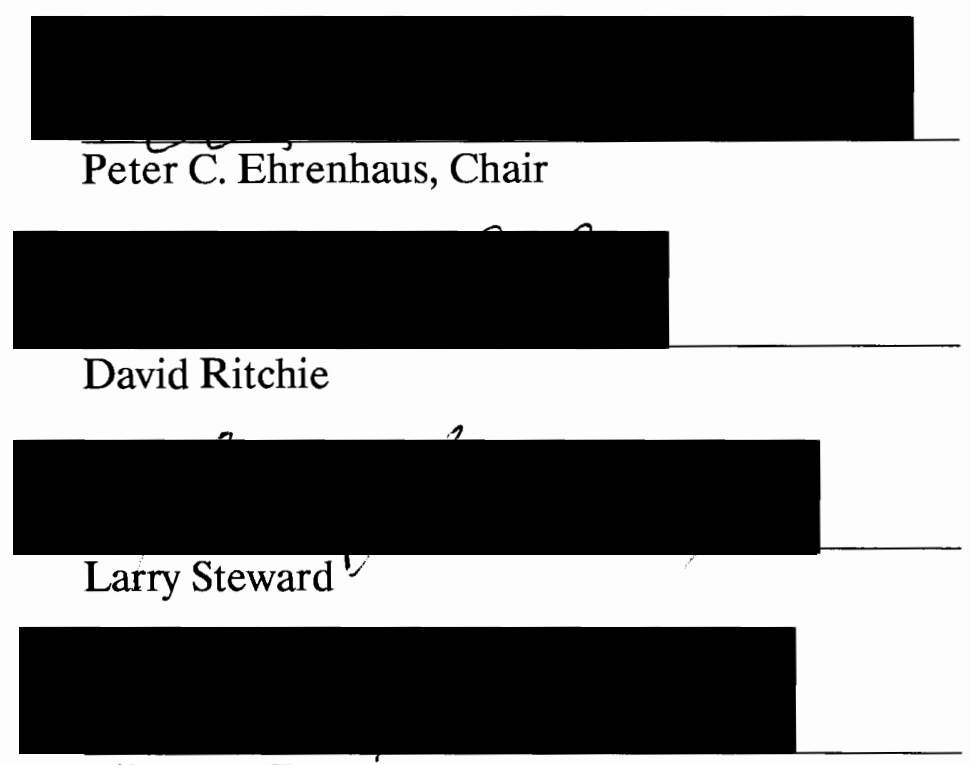

Eileen M. Brennan

\section{APPROVED:}

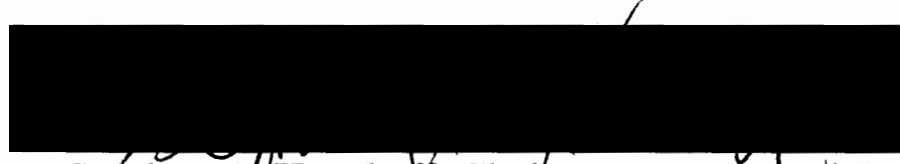

Stephen A//Kosokoff, Chair, Departmentof Speech Communication

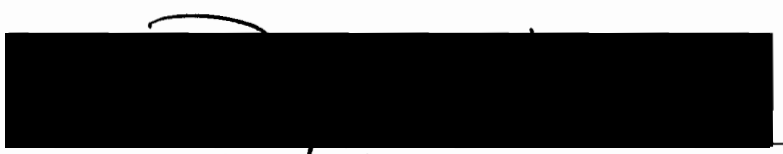

Roy W. Koch, Vice Provost for Graduate Studies and Research 


\section{TABLE OF CONTENTS}

\section{CHAPTER}

PAGE

I INTRODUCTION . . . . . . . . . . . . . . . . . 1

Focus of the Study . . . . . . . . . . . . . . . . 2

Purpose of the Study . . . . . . . . . . . . . . . 3

Organization of Subsequent Chapters . . . . . . . . . 3

II OVERVIEW OF THE LITERATURE . . . . . . . . . . 4

Overview of the Literature on Metaphor . . . . . . . . . 4

Research Goal . . . . . . . . . . . . . . . . . 7

Definitions of Key Concepts $\quad$. . . . . . . . . . . . . . 8

On Not Defining Conflict . . . . . . . . . . . . 8

Conceptual Metaphor . . . . . . . . . . . . 8

Structural Metaphor . . . . . . . . . . . . . . . 9

Ontological Metaphor . . . . . . . . . . . 10

Orientational Metaphor . . . . . . . . . . . 11

Satellite Metaphor . . . . . . . . . . . . 11

Research Questions . . . . . . . . . . . . 12

III METHODOLOGY . . . . . . . . . . . . . . 14

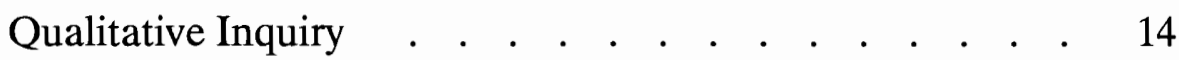

The Interview Schedule . . . . . . . . . . . . . 15

Respondents . . . . . . . . . . . . . . . . 17 
Preliminary Information Given to Respondents . . . . 18

The Pre-Interview . . . . . . . . . . . . . . . 19

The Interview . . . . . . . . . . . . . . . . 21

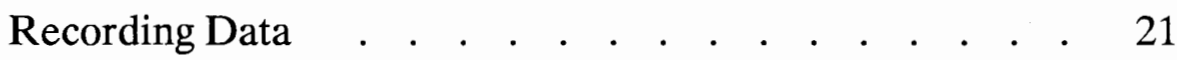

Transcription . . . . . . . . . . . . . . . . 22

Data Analysis . . . . . . . . . . . . . . . . 22

IV DESCRIPTION AND ANALYSIS . . . . . . . . . . . 26

Introduction . . . . . . . . . . . . . . . . . 26

Description . . . . . . . . . . . . . . . . . 26

Structural Metaphors and Their Satellites . . . . 26

Ontological Metaphors and Their Satellites . . . . 37

Orientational Metaphors and Their Satellites . . . . 41

Analysis . . . . . . . . . . . . . . . . . . 48

$\mathrm{V}$ CONCLUSIONS . . . . . . . . . . . . . . 55

Introduction . . . . . . . . . . . . . . . . . 55

Implications . . . . . . . . . . . . . . . . . 55

Limitations of This Study . . . . . . . . . . . . 56

Benefits of Using Naturalistic Research Methods . . . . 57

Suggested Directions for Future Research . . . . . 57

REFERENCES . . . . . . . . . . . . . . . . . . . . . 62 
APPENDICES . . . . . . . . . . . . . . . . . . . . . 65

A INTERVIEW SCHEDULE . . . . . . . . . . . . . 65

B INFORMED CONSENT FORM . . . . . . . . . . . 71 


\section{CHAPTER I}

\section{INTRODUCTION}

Through symbolic interaction, individuals create an understanding of the context in which they operate. As people communicate with each other, they conceptualize the world around them, and use these concepts to shape their perceptions, thoughts, and actions. Lakoff and Johnson state:

Our concepts structure what we perceive, how we get around in the world, and how we relate to other people.... Since communication is based on the same conceptual system that we use in thinking and acting, language is an important source of evidence for what [our basic conceptual] system is like. $(1980$, p. 3)

Lakoff and Johnson (1980) further suggest that our ordinary conceptual system is fundamentally metaphorical in nature. Most people relate to metaphor as an imaginative poetic device rather than a characteristic of everyday language. To the contrary, Lakoff and Johnson argue that metaphor is pervasive in everyday language and life, defining our everyday realities. "... the way we think, what we experience, and what we do every day is very much a matter of metaphor" (Lakoff $\&$ Johnson, 1980, p. 3). Conceptual metaphors influence our perceptions and therefore affect our definitions of reality, our behavior, and our ability to relate to one another.

It seems that our ability to relate to one another might benefit from the influence of some different conceptual metaphors. According to the United States 
Census Bureau, for every two U.S. couples that were married over the last decade, one U.S. couple filed for, and was granted, a divorce (U.S. Bureau of the Census, 1990, Table No. 133). Here in the State of Oregon, the divorce rate has climbed to sixty six percent for the past two years, with divorces usually occurring after only seven years of marriage (U.S. Bureau of the Census, 1990, Tables No. 131 and No. 133). During 1988 alone, Oregon licensed 22,600 marriages, while granting 14,900 divorce decrees, (U.S. Bureau of the Census, 1990, Table No. 133).

\section{FOCUS OF THE STUDY}

The impetus for this thesis arises from this author's interest in the relationship between how people perceive their interpersonal conflicts and the language they use to talk about the conflicts they experience. As a source of conflict, marital relationships provide an ample amount of conflict experiences to be discussed. "Since the needs, desires, and ambitions of people involved in close relationships cannot always be synchronized, some form of conflict is inevitable in close relationships such as marriage" (Fitzpatrick, 1988, p. 137).

The marital dyad is a rich source of conflict, and this study will concentrate on the language married people use to talk about the conflict they experience in their relationship with their spouses. In this thesis, I examine respondents' verbal descriptions of marital conflict and identify the metaphoric structure of that discourse. 


\section{PURPOSE OF THE STUDY}

The purpose of this study is to investigate metaphoric structure revealed during discussions about conflict, and to pose the general question: What conceptual metaphors do married individuals use in discussing their marital conflict?

\section{ORGANIZATION OF SUBSEQUENT CHAPTERS}

Chapter II, Overview of the Literature, locates the assumptions with which this thesis operates. It reviews the operating assumptions of qualitative, interpretive research, and then reviews the literature regarding metaphor that relates to this study. Chapter II also elaborates upon the goal of this research, providing complete definitions for key concepts, and presenting the research questions for the study.

Chapter III, Methodology, describes the development of the interview schedule used in this study, the respondents, and the procedures followed for data collection and analysis.

Chapter IV, Description and Analysis, groups and describes the data collected during the interviews, and reports the findings of data analysis.

Chapter V, Conclusions, discusses the implications and limitations of this study, and suggests directions for further research. 


\section{CHAPTER II}

\section{OVERVIEW OF THE LITERATURE}

In this chapter, I review the operating assumptions of qualitative research, provide an overview of the literature regarding metaphor analysis, and discuss the primary source upon which this study relies. Finally, I elaborate upon the goal of the research, providing complete definitions for key concepts, and presenting the research questions for this study.

\section{OVERVIEW OF THE LITERATURE ON METAPHOR}

In keeping with the theory that language influences our perception of reality, Lakoff and Johnson assert that "... much of our ordinary conceptual system and the bulk of our everyday conventional language are structured and understood primarily in metaphorical terms" (1980, p. 286). Lakoff and Johnson propose that most of our ordinary conceptual systems are metaphorical in nature, and that these metaphoric conceptual systems are reflected in our every day language. Each concept is metaphorically structured, and consequently, the language used to describe it is metaphorically structured.

Accordingly, Fainsilber and Ortony (1987) suggest that:

... one would have to reject the classical Aristotelian view of metaphor as merely linguistic decoration, in favor of a view that accords it an indispensable communicative function.... In theory, there are at least 
three communicative functions that metaphor may serve. First metaphors may allow one to express that which would be difficult or impossible to express if one were restricted to literal uses of language. (p. 240)

Secondly, metaphors constitute a compact means of communication by conveying chunks of information rather than discrete units. Finally, in their 1987 study of metaphorical uses of language in the expression of emotions, Fainsilber and Ortony found that:

... more intense emotional states not only generated more metaphors, but also resulted in richer and more vivid metaphors [suggesting that] metaphors may help capture the vividness of phenomenal experience [by painting] a richer and more detailed picture of our subjective experience than might be expressed by literal language (p. 248).

Glucksberg (1989) concurs with Fainsilber and Ortony, stating that "metaphors permit more precise and informative communication than do literal expressions" (p. $125)$.

Expanding upon metaphoric uses in communication, MacCormac (1985) states that "formulators of metaphor ... intentionally employ language to suggest new possibilities for meaning" (p.160). First of all, MacCormac proposes that metaphors are instruments for the stimulation of emotions. "The kind of emotions that they produce ... may vary from individual to individual according to the context in which each individual receives the metaphor" (1985, p. 160).

Moreover, MacCormac suggests that metaphors not only force us to respond with our emotions, but encourage us to imagine, to speculate, to produce a questioning attitude. "When confronted by a metaphor, we cannot resist attempting 
to understand it ... to wonder about how to comprehend the conflict among the semantic referents of the metaphor" (1985, p. 160).

In addition to stimulating emotions and producing perplexity, MacCormac believes that metaphor has the ability to promote intimacy:

The inventor of the metaphor, when he or she coins it, and the hearer, when he or she achieves comprehension of it, are united in an intimate bond of insight. Both share the intimacy of a new suggestive possibility and perhaps an emotional feeling that is not normally shared in the ordinary use of language.... The mental formation of metaphors constructs a linguistic bridge from the embodied mind to culture. (1985, p. 127)

In summary, new metaphors alter the culture in which we live, and therefore affect the ways humans interact with each other and their environment.

Similarly, Gibbs and Gerrig (1989) acknowledge the significant role metaphor has in maintaining social and personal relationships, and they agree:

... one of the primary functions of metaphor is to evoke a sense of intimacy between speakers and addressees ... and it is context, the common-ground beliefs and knowledge held by speakers and listeners, that makes recovery of these .... meanings so prominent and so much a part of our conscious awareness. (p. 155)

The primary source upon which this study relies is Lakoff and Johnson's (1980)

system for grounding and identifying conceptual metaphors:

Since metaphorical expressions in our language are tied to metaphorical concepts in a systematic way, we can use metaphorical linguistic expressions to study the nature of metaphorical concepts and to gain an understanding of the metaphorical nature of our activities. (Lakoff $\&$ Johnson, 1980, p. 290)

We use metaphoric concepts to make sense out of our life experiences. 
Consider the concept of an ARGUMENT, and the conceptual metaphor ARGUMENT IS WAR. This metaphor is reflected in our every day language (Lakoff \& Johnson, 1980, p. 4):

He ATTACKED EVERY WEAK POINT in my argument.

His criticisms were RIGHT ON TARGET.

If I use that STRATEGY, she'll WIPE ME OUT.

He SHOT DOWN all of my arguments.

I've never WON an argument with him.

As we commonly speak of arguments in terms of war, we consider the person with whom we are arguing to be an OPPONENT. We ATTACK their position and DEFEND our own. We plan and use STRATEGIES, GAINING AND LOSING GROUND. "Though there is no physical battle, there is a verbal battle, and the structure of an argument - attack, defense, counterattack, etc. - reflects this" (Lakoff \& Johnson, 1980, p. 288). In our culture, the ARGUMENT IS WAR metaphor normally structures the language we use, as well as the actions we perform in arguing. Our conventional way of talking about an argument presupposes a metaphor:

The metaphor is not merely in the words we use - it is in our very concept of an argument.... We talk about arguments [in terms of war] because we conceive of them that way - and we act according to the way we conceive of things. (Lakoff \& Johnson, 1980, p. 289)

\section{RESEARCH GOAL}

The goal of this research is to identify and analyze some of the metaphors used by respondents in talking about their marital conflicts, and to illustrate how Lakoff 
and Johnson (1980) can be applied to analyzing respondents' use of metaphoric concepts.

\section{DEFINITIONS OF KEY CONCEPTS}

\section{On Not Defining Conflict}

While definitions of conflict abound, all are fundamentally problematic for a study of this nature. All formal definitions have metaphoric entailments. Consider one commonly accepted definition of the term, "An expressed struggle between at least two interdependent parties who perceive incompatible goals, scarce rewards, and interference from the other party in achieving their goals" (Hocker \& Wilmot, 1985, p. 23). The language of this definition presupposes a conceptual metaphor for conflict ("Conflict is competition"). The metaphoric nature of language makes it is impossible to eliminate all metaphor from an accurate definition of the term "conflict". Since it is not possible to define the term "conflict " in a manner that is free of metaphoric concepts, this study will not define "conflict" so that metaphors are not suggested as part of a definition. In this study, respondents will reveal their own definitions of "conflict".

\section{Conceptual Metaphor}

A conceptual metaphor is one embodying a concept, either structural, ontological, or orientational, that influences our perception of reality. Conceptual metaphors are cognitive models, not usually linguistically expressed, that we use to help us understand, organize and reason about our knowledge and experiences. 


\section{$\underline{\text { Structural Metaphor }}$}

Structural metaphors use one highly structured, clearly delineated, nonmetaphoric concept to structure aspects of a second concept. In order to understand one concept in terms of another, nonmetaphoric concept, one must have appropriate knowledge of the nonmetaphoric concept:

A metaphor with the name A IS B is a mapping of part of the structure of our knowledge of source domain B onto target domain A.... In order to understand a target domain in terms of a source domain, one must have appropriate knowledge of the source domain. ... Our knowledge of a domain allows us to draw inferences about that domain. (Lakoff \& Turner, 1989, p. 59)

For example, the metaphor INTERPERSONAL CONFLICT IS THE PROCESS

OF COOKING is dependent upon our knowledge of the aspects of cooking. A general knowledge of cooking provides a skeletal structure specific enough to distinguish cooking from other types of activity, yet not so specific as to rule out any particular manner of cooking. Such options allow one to enhance and alter the metaphor in order to arrive at new understandings of the "target domain". As a result, understanding interpersonal conflict in terms of cooking promotes a rich and varied conceptualization of interpersonal conflict.

Lakoff and Johnson explain the structural metaphor ARGUMENT IS WAR in the following manner:

The essence of metaphor is understanding and experiencing one kind of thing in terms of another. It is not that arguments are a subspecies of war. Arguments and wars are different kinds of things - verbal discourse and armed conflict - and the actions performed are different kinds of actions. But ARGUMENT is partially structured, understood, performed, and talked about in terms of WAR. (1980, p. 289) 
The structural metaphor ARGUMENT IS WAR conceptualizes an argument in terms of another concept that is understood more readily - war.

Structural metaphors allow for the exploration and the elaboration of one concept within the structural terms of a another concept. However, when one concept is "structured" by another concept, the structuring is actually only partial. The metaphor can be extended in some ways, but not in others. Metaphoric structuring "... is partial, not total. If it were total, one concept would actually be the other, not merely be understood in terms of it" (Lakoff \& Johnson, 1980, p. 13). A conceptual metaphor can focus our attention on, or "highlight", some aspects of a concept, and at the same time distract us from focusing on other aspects of the same concept that are inconsistent with the structural metaphor. Lakoff and Johnson further explain:

... in the midst of a heated argument, when we are intent on attacking our opponent's position and defending our own, we may lose sight of the cooperative aspects of arguing. Someone who is arguing with you can be viewed as giving you his time, a valuable commodity, in an effort at mutual understanding. But when we are preoccupied with the battle aspects, we often lose sight of the cooperative aspects. (1980, p. 10)

Ontological Metaphor

The ontological metaphor also "partially" organizes a concept in terms of an object. Human experience with physical objects provides the basis for an ontological metaphor. Lakoff and Johnson explain:

Once we can identify our experiences as entities or substances, we can refer to them, categorize them, group then, and quantify them - and, by this means, reason about them. 
When things are not clearly discrete or bounded, we still categorize them as such, e.g., mountains, street corners, hedges, etc. ... Human purposes typically require us to impose artificial boundaries that make physical phenomena discrete just as we are: entities bounded by a surface. (1980, p. 25)

The ontological metaphor "The MIND is a MACHINE" provides a metaphorical model for what the mind is, and allows the creator of the metaphor, as well as the receiver, to pay attention to many aspects of the mental experience:

The MACHINE metaphor gives us a conception of the mind as having an on-off state, a level of efficiency, a productive capacity, an internal mechanism, a source of energy, and an operating condition. (Lakoff $\&$ Johnson, 1980, p. 27)

\section{Orientational Metaphor}

Orientational metaphors use spatial orientations to organize concepts with respect to other concepts:

Orientational metaphors give a concept a spatial orientation; for example HAPPY is UP. The fact that the concept HAPPY is oriented UP leads to English expressions like "I'm feeling UP today." (Lakoff \& Johnson, 1980, p. 14)

Spatial orientations are based in our human physical experience, developed from the fact that our human bodies operate in a physical environment. The most typical spatial orientations are up-down, in-out, front-back, on-off, deep-shallow, and central-peripheral. (Lakoff \& Johnson, 1980, p. 14)

\section{Satellite Metaphor}

Satellite metaphors are verbal expressions of conceptual metaphors.

"[Conceptual metaphors] are given implicit expression by the occurrence of their 
satellite, or linguistic, metaphors" (Levin, 1988, p. 5). Conceptual metaphors fashion our perception of reality and the satellite metaphors provide testimony in our actual speech.

Lakoff and Johnson organize metaphors in terms of the inferable and the observable, the inferable being the conceptual metaphor and the observable being the satellite metaphor. Referring once again to the structural metaphor ARGUMENT IS WAR, Lakoff and Johnson point out:

The normal way for us to talk about attacking a position is to use the words 'attack a position'.... The language of argument is not poetic, fanciful, or rhetorical, but rather literal.... The concept is metaphorically structured, the activity is metaphorically structured, and, consequently, the language is metaphorically structured. $(1980$, p. 289)

The structural metaphor INTERPERSONAL CONFLICT IS THE PROCESS OF COOKING might produce the following satellite metaphors:

\author{
Don't get STEAMED! \\ I was BURNED. \\ That really FRIES me! \\ He lets things SIMMER before he gets BOILING mad. \\ She STEWED FOR HOURS. \\ Oh, put a LID ON IT!
}

\title{
RESEARCH QUESTIONS
}

Lakoff and Johnson (1980) suggest that language is metaphorically structured, and therefore, not only our language, but our thoughts and actions, are metaphorically structured as well. My practical and theoretical interests in the 
metaphoric conceptualization of reality generated two research questions. The questions address the individual, and the individual as part of a couple:

1. What structural, ontological, and orientational metaphors are manifested in respondents' reports of marital conflict?

2. Do individuals within the same couple use metaphor similarly?

Chapter III, Methodology, will describe the development of the interview schedule, introduce the respondents, and explain the procedures for data collection and analysis followed in this study. 


\section{CHAPTER III}

\section{METHODOLOGY}

Chapter III, Methodology, will review the steps of qualitative inquiry, describe the development of this study's interview schedule, introduce the respondents, and describe the procedures followed for data collection and analysis.

\section{QUALITATIVE INQUIRY}

This study is qualitative in design. In The Long Interview (1988), Grant McCracken reveals a four step qualitative research process designed to give the researcher an "agile instrument with which to capture how the respondent sees and experiences the world" (p. 65). The first step is to review the literature. This enables the researcher to define problems, assess data, exercise skepticism, acknowledge preconceptions, and construct an effective interview questionnaire.

The second step in this qualitative research process consists of a review of categories where the researcher begins to use the self as an instrument of inquiry. "The object is to draw out of one's own experience the systematic properties of the topic, separating the structural from the episodic, and the cultural from the idiosyncratic" (McCracken, 1988, p. 32). This step also aids in interview questionnaire construction, as well as data analysis, and establishes the necessary 
"distance" from the topic of study allowing the researcher to view familiar data in unfamiliar ways.

Step three is the construction of the interview questionnaire. The questionnaire ensures that the researcher cover similar terrain for each respondent, and ensures that prompts necessary for maintaining "distance" are situated throughout the interview. The questionnaire also establishes channels for the direction and scope of discourse, and enables the researcher to direct attention to the respondent's testimony listening for terms, assumptions, and interrelationships.

The final step is the analysis of the qualitative data:

The investigator comes to the undertaking with a sense of what the literature says ought to be there, a sense of how the topic at issue is constituted in his or her own experience, and a glancing sense of what took place in the interview itself. ... the investigator must be prepared to glimpse and systematically reconstruct a view of the world that bears no relation to his or her own view or the one evident in the literature. (McCracken, 1988, p. 42)

The goal of this study's data analysis is to identify some of the categories of metaphoric concepts evident in the respondents' discourse.

\section{THE INTERVIEW SCHEDULE}

According to McCracken (1988), the use of an interview schedule, or "questionnaire" is "indispensable" for the purposes of a qualitative interview (p. 24). In keeping with McCracken's qualitative approach to research, data for this study were gathered through moderately scheduled interviews. The primary questions on the Interview Schedule focus on the "Topics" of marital conflict, the "Settings" of 
conflict, the "Process" of conflict, the "Responses" to conflict, and the

"Communication" during marital conflict (see Appendix A). Questions were designed to be general and open-ended in order to encourage respondents to talk about experiences and perceptions that were most important to them. Categories for additional probing were listed under each primary question. During the interview, I used each category as a prompt for further questioning when needing the respondent to further elaborate on a question.

This moderately scheduled interview was treated as a flexible tool of inquiry allowing for the possibility of rearranging areas of questioning to fit the respondent. Lofland and Lofland (1984) point out the importance of flexibility in the interview schedule:

... [an interview] guide is not a tightly structured set of questions to be asked verbatim as written, accompanied by an associated range of preworded answers.... You want interviewees to speak freely in their own terms about a set of concerns you bring to the interaction, plus whatever else they might introduce. (p. 59)

Two pre-test interviews revealed the alterations and refinements necessary to produce the Interview Schedule used in this study. The first pre-test interview revealed that the original format for the interview schedule was far too structured. The complete, carefully planned, specific questions that made up the interview schedule left little room for the respondent to discuss and explore areas of interest to $\mathrm{him} / \mathrm{her}$.

After modifying the interview schedule format to include very general primary questions followed by specific secondary questions, the second pre-test interview 
still revealed the secondary questions to be too limiting. Therefore, the majority of the secondary questions were transformed into one word prompts designed to help the interviewer formulate probing questions that would solicit further elaboration from the respondent as required.

The third version of the interview schedule was also tested, and with success, generating natural and insightful responses from a third respondent. This third and final version, the moderately scheduled interview used in this study, was effective in gathering useful data from all eight respondents.

\section{RESPONDENTS}

Recruiting respondents to participate in this study was the final preparation for the interviews. Prior to soliciting respondents, I developed a list of preconditions with which potential respondents would have to comply before being asked to participate in this study. The preconditions were as follows:

1. The couple would have to have been married for a minimum of one year to increase the chances of the couple being familiar with marital conflict.

2. Each member of the couple should have previously been introduced to the researcher to increase the chances of the potential respondent feeling comfortable with the idea of disclosing "private" information to the researcher. 
For qualitative interviewing, McCracken (1988) suggests that respondents be "few in number (i.e., no more than eight)", and that "They should not have special knowledge (or ignorance) of the topic under study."

Upon considering the twelve couples to whom I had been introduced through acquaintances, friends and neighbors, at political and social events over the last year, four couples best met my preconditions. I contacted these four couples and asked them to participate in this study. After agreeing to participate, each of the eight individuals was interviewed privately, and voluntarily responded to the moderately scheduled interview questions. Four of the respondents were male, four were female. The youngest respondent was twenty eight, the eldest, forty. Six out of the eight respondents were in their thirties.

\section{PRELIMINARY INFORMATION GIVEN TO RESPONDENTS}

I contacted each respondent at his or her home by telephone, identified myself, and asked each person if he or she would be interested in being privately interviewed for a study about marital conflict. I either explained, or reminded them, that I was a graduate student in the Speech Communication Department at Portland State University writing my master's thesis, and that I was particularly interested in how people manage marital conflict. I further explained that I expected each private interview to take about an hour of their time, that I would like to tape record the interview, and that all of the information they would give me would remain confidential. 
All but one of the respondents immediately agreed to participate. One gentleman asked if he could provide me with an answer the following morning, and early the next day he and his wife both came to my home to assure me that they would be happy to participate.

Once the respondents agreed to volunteer, we would then schedule a time and location to conduct the interview at their convenience. Five respondents preferred to be interviewed in my living room, and three found it more convenient for me to come to their home. I made it very clear that I was flexible, and that I wanted whatever situation would work best for them.

\section{THE PRE-INTERVIEW}

When I met with each respondent, I reviewed that I was writing my master's thesis and that my interests were focused on conflict management, specifically how people that are married to one another perceive conflict in their marriage. Then I explained the structure of the interview - that I would first ask about "typical" conflict in the marriage, and that then I would ask them to discuss a recent marital conflict of their choice. I explained that there were no right or wrong answers, and that they could answer in as little or as much detail as made them comfortable. I pointed out that "I am most interested in your experiences and your perceptions of those experiences, and therefore I am leaving the definition of the term 'conflict' totally up to you." 
Respondents were encouraged to "... feel free to stop me at any time if you don't understand my questioning, or if you want to pass on a particular line of questioning and move on to something else." I reminded them that all of the information they were about to give me would remain confidential, and that whenever I spoke about this research, or wrote about it, I would use their age, gender, and the number of years they've been married to identify the data. I further explained that being able to tape record these interviews was very helpful to me, and that I would be the only person to listen to the tapes. At this time I would ask the respondent if he or she had any questions.

After answering the respondent's questions (few respondents had questions), I presented the respondent with two copies of the Informed Consent Form (see Appendix B). I asked them to read both copies, and if they were comfortable with what was written, to sign and date both copies, keeping one for their own records and returning the second copy to me for my records.

Finally, I explained that in the interest of being very thorough, I would like to ask them a few demographic questions before we began - their age, gender, and how long they had been married to their current spouse. Once this information was noted on the cassette tape to be used to record their interview, the interview began in earnest. 


\section{THE INTERVIEW}

I conducted each interview myself during the summer and fall term of 1992. The length of the actual interviews varied from one to two hours. Each individual interview was conducted privately in surroundings that were comfortable and convenient for the respondent. I purposely scheduled only one interview on any given day, because I wanted my mind to be fresh, clear and focused for each respondent.

\section{RECORDING DATA}

Rather than take extensive notes, I tape recorded each interview so I could give my full attention to each respondent and his/her perceptions. However, I did take marginal notes on a clean copy of the interview schedule during each interview to insure that all relevant questions and sub-categories were addressed. Each of the eight interviews was recorded on a separate audio cassette tape. I did not encounter any problems with this process. The tape recorder, microphone, batteries, and cassettes worked well every time. I found that after the first question, usually while commenting on the second or third probe from the interviewer, the respondents seemed to ignore, or become comfortable with, the presence of the tape recorder. After a short time into each interview, the respondent appeared to relax and feel comfortable discussing his or her perceptions of marital conflict. 


\section{TRANSCRIPTION}

The interview tapes were transcribed within two days after each interview.

Since I was careful to schedule the interviews in locations that provided quiet surroundings and privacy, the interview tapes included very little background noise or interruptions. These conditions made transcribing the eight tapes an unencumbered process. The transcriptions were assigned the same identifying information (age, gender, and years married) as the corresponding interview tape.

\section{DATA ANALYSIS}

Data analysis occurred throughout data collection. Lofland and Lofland (1984) suggest that the research approach of simultaneous data collection and beginning data analysis is more productive than the research approach of dividing data collection into one phase and analysis into another:

... analysis and data collection run concurrently for most of the time expended on the project, and the final stage of analysis (after data collection has ceased) becomes a period for bringing final order to previously developed ideas. Contrast this with the ... situation wherein the researcher, after data collection has ceased, has to begin to make some kind of coherent sense out of the mass of running descriptions, documents, and so on. (p. 131)

Bogdan and Taylor (1984) also discuss the relationship between data collection and on-going analysis:

Data collection and analysis go hand-in-hand. Throughout participant observation, in-depth interviewing, and other qualitative research, researchers keep track of emerging themes, read through their field notes or transcripts, and develop concepts and propositions to begin to make sense out of their data. (p. 128) 
Analysis was continually in process. As I listened to the respondent's information during each interview, as I modified the way I phrased certain questions based on information received in earlier interviews, and as I reflected on each interview as I transcribed it, analysis was in process.

After transcribing the interviews, I made a copy of each transcription. The original transcriptions were kept in a master file.

The copy of each transcription was analyzed for the presence of satellite metaphors manifesting structural, ontological, and orientational metaphors. I made a list of each respondent's structural, ontological, and orientational metaphors. I then arranged the respondent's corresponding satellite metaphors under each appropriate conceptual metaphor. Each list identified a specific respondent's use of structural, ontological, and orientational satellite metaphors.

My next project was to create another listing of all the structural, ontological and orientational metaphors revealed in the transcriptions of all the respondents. Again, I used the conceptual metaphors as headings, and listed all of the respondents' corresponding satellite metaphors under each heading (each satellite metaphor's respondent identified by age, gender, and years married). With this list, I could decipher which respondents contributed to each structural, ontological, and orientational metaphor.

Since elementary analysis was continuous throughout the process of identifying and labeling the data, possible coding categories for structural, ontological, and orientational metaphors were already beginning to emerge. I placed each emergent 
coding category on a separate index card, and spread all of the cards out on a table. By re-ordering the cards, I could explore the conceptual feasibility of various category schemes. As I tested the viability of the emergent categories, workable coding categories became fewer in number and more clearly delineated.

Once the coding categories for the structural, ontological, and orientational metaphors were developed, the next step was to place each individual piece of data, identified from the transcripts, on a separate index card. Every satellite metaphor interpreted for each inferred structural metaphor, ontological metaphor, and orientational metaphor was singularly written on an individual index card, and the source respondent for each piece of information was also noted on the same card in terms of age, gender, and years married. These data cards were then arranged, and rearranged again and again, under the coding categories.

Bogdan and Taylor (1984, p. 138) cite five steps in the coding process:

1. Develop coding categories.

2. Code all the data.

3. Sort the data into the coding categories.

4. See what data are left out.

5. Refine your analysis.

Most of the coding categories that originally caught my attention remained as significant categories in the final analysis. Bogdan and Taylor also suggest, "By studying themes, constructing typologies, and relating different pieces of data to each other, the researcher gradually comes up with generalizations" (1984, p. 134).

Finally, all index cards showing information related to a particular coding category were taped onto a large piece of paper titled with that coding category. In 
cases where one piece of data fell under more than one category, copies of the data card were made so that relevant information was included under all coding categories.

The following chapter presents and analyzes the data collected in this study. 


\section{CHAPTER IV}

\section{DESCRIPTION AND ANALYSIS}

\section{INTRODUCTION}

Chapter IV presents and analyzes data collected in this study. DESCRIPTION reveals the satellite metaphors interpreted from the respondents' discourse, and suggests the implied structural, ontological, and orientational metaphoric concepts used by the respondents during their discussions of marital conflict. ANALYSIS will focus on patterns of respondents' use of structural, ontological, and orientational metaphors.

\section{DESCRIPTION}

Structural Metaphors and Their Satellites

The satellite metaphors that respondents used as they described their experiences with marital conflict suggested the respondents' reliance upon structural, ontological, and orientational metaphors. I will first provide a list of the structural metaphors used by respondents, and a sample of the observable satellite metaphors under each structural heading. A listing of the ontological metaphoric concepts and their referential satellite metaphors will follow, and finally I will 
provide a list of the orientational metaphors respondents used along with a sample of corresponding satellite metaphors under each orientational heading.

I have identified the respondents' use of structural metaphors to include:

1. CONFLICT IS A JOURNEY

l.a. CONFLICT IS FOOT TRAVEL

1.b. CONFLICT IS AN OCEAN VOYAGE

1.c. CONFLICT IS A METAPHYSICAL EXPERIENCE

2. CONFLICT IS COMPETITION

2.a. CONFLICT IS WAR

2.b. CONFLICT IS BOXING

3. CONFLICT IS A VOLCANIC ERUPTION

4. CONFLICT IS A PERFORMANCE

Beginning with the structural metaphoric concept CONFLICT IS A JOURNEY, this metaphoric concept was addressed through two, more specific structural metaphors, CONFLICT IS FOOT TRAVEL and CONFLICT IS AN OCEAN VOYAGE.

Using the structural metaphor CONFLICT IS FOOT TRAVEL, one of the respondents stated:

As time goes on, she does take ONE STEP CLOSER to where I am, or I take ONE STEP CLOSER to where she is, and so the next time that topic comes up we're already closer. I don't think she's MOVED so much, but I have.... It also depends on WHICH WAY WE'RE GOING. ... I would GET FARTHER if I wouldn't question her so 
often, if I were more DIRECT IN MY APPROACH. (M, 31, married 1 $1 / 2 \mathrm{yrs})$

This man's spouse also referred to conflict as a journey on foot, suggesting that "One of us will have GONE ONE STEP TOO FAR" (F, 30, married 1 1/2 yrs). She also made some general references to conflict as travel, or a journey:

I want him to at least understand WHERE I'M COMING FROM. ... I don't want to COME ACROSS as 'bossy'.... [Our conflict] usually has a STARTING POINT, and if we GO VERY FAR I can cry. (F, 30, married $11 / 2$ yrs)

One of the men provided an elaborate foot travel metaphor:

[My wife and I] usually WALK DOWN THE SAME PATHWAY. Sometimes we GO TWO DIFFERENT DIRECTIONS. [Conflict] is a JOURNEY where there's a PATH that you take. Once you GO DOWN THE PATH, there's really NO TURNING BACK. It involves you, and affects you, and therefore CHANGES YOUR COURSE. It's sort of an ADVENTURE where you GO DOWN ONE PATH, and see what happens, and make the best of it.... The PATHS [my wife and I] take to resolve the conflict are often different. They're parallel towards a resolution, but I'd like us to be ON THE SAME PATH. (M, 32, married 2 yrs)

This same man also structured his concept of conflict with the metaphoric concept CONFLICT IS A METAPHYSICAL EXPERIENCE:

I try to DETACH MYSELF and MOVE AWAY from the situation. I have an OUT-OF-BODY EXPERIENCE, LOOKING ON and providing an automatic response to her concerns. Once the conflict is over, I then RESUME MY IN-BODY EXPERIENCE. (M, 32, married 2 yrs)

This man's spouse made only one reference to the metaphoric concept CONFLICT IS A JOURNEY, and in general terms, stating "[Conflict] can end in a 'GO YOUR OWN SEPARATE WAY' kind of thing" (F, 28, married $2 \mathrm{yrs}$ ). 
Also implying the metaphor CONFLICT IS A JOURNEY, one respondent used the structural metaphor CONFLICT IS AN OCEAN VOYAGE: "I go through a SEA OF EMOTIONS. ... I have not ever wanted to MAKE WAVES. He doesn't like to MAKE WAVES either. ... Laughter is often FUEL FOR MY CONTINUING" (F, 38, married 11 yrs). A second sailor said: "I tend to cross my arms when I'm ON A TACK I'm not very movable on" (M, 31, married 8 1/2 yrs).

Overall, three women and three men structured their concept of conflict with the concept of a journey. Specifically, one woman and two men referred to foot travel, a second woman and a third man made references to conflict as a voyage over water, and two of the women discussed conflict in general terms of travel.

As couples, two used the metaphoric concept CONFLICT IS A JOURNEY. The wife in one couple made general conceptual references to travel while her husband created specific satellite metaphors regarding journeys on foot, and metaphysical travel. In a second couple, both spouses created satellite metaphors specifically referring to journeys on foot.

The structural metaphoric concept CONFLICT IS COMPETITION was typically addressed as one of two more specific structural metaphors as well: CONFLICT IS WAR, and CONFLICT IS BOXING.

The structural metaphor CONFLICT IS WAR was characterized by references to battle tactics and maneuvers:

I go for little VICTORIES. We try to be fairly GUARDED. I just want to ease on into the moment, to RESERVE VALUABLE ENERGY, TRYING TO SURVIVE.... We go away for awhile, and then we both 
calm down enough to understand each other's POSITION. I want to be able to ANTICIPATE this. She thinks she has everything WIRED so that I couldn't possibly have a DEFENSE. . . I I feel SHANGHAIED.... She just wants to KILL OURSELVES UNTIL WE DROP DEAD. I SURRENDER! (M, 32, married 2 yrs)

This man's spouse also used the metaphoric concept CONFLICT IS WAR:

I tend to be AGGRESSIVE, and I will READ HIM THE RIOT ACT. He'll be DEFENSIVE back because he's been ATTACKED. ... I'm ON ATTACK MODE, and that can OBLITERATE the last two years of a good marriage. He just wants to FEND OFF THE ATTACK.... It's AN ATTACK SITUATION. I just WENT ON THE ATTACK, and we went into a verbal BATTLE at that point. ... I'd like to just SQUEEZE THE HEAD OFF a Barbie doll! (F, 28, married 2 yrs)

A second couple structured their concept of conflict with the concept of war:

I'm so intent on FORMING A COMEBACK and DEFENDING MY POSITION that I'm not listening to what she is saying. I end up CUTTING HER OFF. I DEFEAT all communication.... Don't BOMBARD me with questions. Don't BOMBARD me with anything. Asking me questions at this point is SETTING ME UP.... I use a DEFENSIVE posture, PULLING IN, PULLING BACK. If I'M THE ONE WHO'S CHALLENGING, I'll tend to be more forward. If I'm CHALLENGED, I'll PULL BACK. That's my typical MANEUVER. (M, 31, married 11/2 yrs)

We'll ATTACK a problem. Sometimes it takes STRATEGY... I I can feel myself getting DEFENSIVE, and DRAWING THE LINE.... the other will often feel WOUNDED. (F, 30, married $11 / 2$ yrs)

A third man offered a gloomy perspective on conflict through the use of the structural metaphor CONFLICT IS WAR:

I feel RESIGNATION, DEFEAT. I'VE LOST. Forget It. Try again another day.... My argument is DEAD AND BURIED. She's got her rebuttals LINED UP IN A ROW and FIRES THEM OFF ONE BY ONE. (M, 40, married 11 yrs) 
The structural metaphor CONFLICT IS WAR conceptualizes conflict in terms of another concept that is more readily understood - war. Our concept of "war" is grounded in our experience of physical violence, and at times our verbal battles collapse into physical violence. Lakoff and Johnson explain:

Fighting is found everywhere in the animal kingdom .... In fights between two brute animals, scientists have observed the practices of issuing challenges for the sake of intimidation, of establishing and defending territory, attacking, defending, counterattacking, retreating, and surrendering. Human fighting involves the same practices. (Lakoff \& Johnson, 1980, p. 62)

Abiding by Lakoff and Johnson's reasoning, I have also included "predacious" satellite metaphors as evidence for the operation of the structural metaphor CONFLICT IS WAR. Two couples extended the metaphoric concept CONFLICT

IS WAR in predatory terms:

I'm READY TO POUNCE. ... We'll SNAP at each other, and then there's a lot of SCURRYING AROUND going on. There are times when I SEEK HIM OUT. . . I've had a bad day and he's BORN THE BRUNT OF IT. (F, 28, married 2 yrs)

This woman's husband offered:

Sometimes we BASH HEADS. ... She's not TAKING THE BAIT as much any more. (M, 32, married $2 \mathrm{yrs})$

As part of the second couple to extend the metaphoric concept, the wife may have thought of herself as a vulture:

Sometimes I just have to PICK ON somebody. I PICK ON him.... I knew I'd WOUNDED him. (F, 38, married 11 yrs)

The husband may see himself as the carcass:

I'm DEAD MEAT. (M, 40, married 11 yrs) 
All four men referred to the metaphoric concept CONFLICT IS WAR at one time or another. Following are the predacious satellite metaphors used by the other two men:

I have a very SHARP TONGUE. (M, 31, married 1 1/2 yrs)

One is just waiting to TAKE THE OTHER'S HEAD OFF. (M, 31, married $81 / 2$ yrs)

The structural metaphor CONFLICT IS COMPETITION was further supported by satellite metaphors from three couples that identified the more specific structural metaphor CONFLICT IS BOXING:

She'll THROW A ZINGER in at me, or I'll get HIT with a "To-Do List" (M, 32, married 2 yrs)

This man's spouse offered:

First we FIGHT, and then we huff off to our SEPARATE CORNERS. (F, 28, married 2 yrs)

I take an AGGRESSIVE STANCE, like I'm saying "Come on, come on, I'LL TAKE YOU ON!" The whole FIGHT is usually ridiculous. I'm often sorry that we FOUGHT. I hate FIGHTING like that. The FIGHTS are not WORTH IT. . . . Sometimes I want a REMATCH. ... I tell him "You're not my MANAGER! Stop telling me what to do!" Then he'll BACK OFF. (F, 32, married $81 / 2$ yrs)

This woman's husband suggested:

I was BLIND-SIDED! . . I don't need to WIN THE PRIZE. (M, 31, married $81 / 2$ yrs)

I tend to be a WINNER. I want to be a WINNER.... MY WHOLE BODY REACTS with a lot of tension. I'M REALLY STRONG. I plant myself ON MY FEET and FEND HIM OFF, or he knows to BACK OFF. (F, 38, married 11 yrs)

Her spouse described his perceived role in marital conflict: 
I sit there like a PUNCHING BAG. I'll be the BAG so my wife can vent her anger. ( $M, 40$, married $11 \mathrm{yrs})$

The fourth couple also used the concept of competition to metaphorically structure their concept of conflict. Instead of boxing, however, the husband used satellite metaphors making reference to the sport of baseball, and the wife used satellite referring to either volleyball or doubles tennis:

She's in LEFT FIELD and I'm in RIGHT FIELD. It's like "Are you even PLAYING BASEBALL dear?" . . [Conflict] can be very TIRING, PHYSICALLY draining. (M, 31, married 1 1/2 yrs)

You don't want to come over to MY SIDE OF THE NET and I don't want to come over to YOUR SIDE OF THE NET. Sometimes I feel like we're on OPPOSITE TEAMS. (F, 30. married $11 / 2 \mathrm{yrs}$ )

Overall, my interpretation of the respondents' discourse suggests that all eight respondents used the structural metaphor CONFLICT IS COMPETITION to organize their concept of marital conflict in one way or another. Specifically, all four men and three of the women created satellite metaphors structuring conflict as WAR. In addition, three men and three women created satellite metaphors structuring their concept of conflict as a BOXING MATCH.

As couples, three couples had both spouses inferring the metaphoric concept CONFLICT IS WAR, and three couples had both spouses inferring the metaphor CONFLICT IS BOXING. Two of the four couples used both CONFLICT IS WAR and CONFLICT IS BOXING to structure their concepts of marital conflict. 
Another structural metaphor employed by respondents in this study was that of CONFLICT IS A VOLCANIC ERUPTION. Only one of the men used satellite metaphors referring to this structural metaphor:

My family calls me VESUVIUS. I found out when we got the dog that I could become the VOLCANO. I see RED. I feel the HEAT COMING UP. Luckily it BLOWS out, and then there needs to be this COOLING DOWN PERIOD. (M, 31, married 1 1/2 yrs)

Two out of the four women used satellite metaphors referring to volcanic activity:

If it's really a HEATED situation, I can feel it COMING UP THROUGH MY VEINS almost, this warm sensation of wanting to really scream and be angry. (F, 28, married 2 yrs)

[Conflict] may ERUPT more often now. I'm not letting the anger build and build until it BLOWS LIKE MOUNT ST. HELENS. If I do then it all ERUPTS again. (F, 32, married 8 1/2 yrs)

Overall, one man and two of the women structured marital conflict as a volcanic eruption. No two spouses used this structural metaphor together as a couple.

One woman used satellite metaphors that could indicate the operation of the structural metaphor CONFLICT IS A VOLCANIC ERUPTION or the operation of the structural metaphor CONFLICT IS PRESSURE COOKING:

Typically it's just a BIG BLOW UP, PRESSURE. Something little starts and then everything BLOWS.... Most of the time, he let's me BLOW OFF STEAM and the STEAM starts to subside.... It's usually a PRESSURE thing. I can feel the PRESSURE BUILDING in my mind. I'll get real angry and upset, and I'll BLOW, yelling and screaming. (F, 38 , married 11 yrs)

This woman's satellite metaphors could be referring to either the structural concept of volcanic eruption or the structural concept of cooking, or referring to the concept 
of heat in combination with water in general. All conceptual metaphors are grounded in our own personal experience, both physical and cultural, as Lakoff and Johnson explain:

[Conceptual metaphors] are not randomly assigned. A metaphor can serve as a vehicle for understanding a concept only by virtue of its experiential basis.... [Further], it is hard to distinguish the physical from the cultural basis of a metaphor, since the choice of one physical basis from among many possible ones has to do with cultural coherence. $(1980$, p. 19)

This woman's satellite metaphors made general references to a structural concept that included heat and steam. Therefore, without further knowledge of this woman's field of experience, this researcher can only guess which specific metaphoric concept, if any, was structuring the woman's description of marital conflict. Lakoff and Johnson further explain:

We do not know very much about the experiential bases of metaphors. Because of our ignorance in this matter, we have described the metaphors separately, only later adding speculative notes on their possible experiential bases. We are adopting this practice out of ignorance, not out of principle. (1980, p. 19)

On previous pages, this chapter discussed the structural metaphor CONFLICT IS COMPETITION, and identified one woman's satellite metaphors as including references to either the sport of "volleyball" or "doubles tennis":

You don't want to come over to MY SIDE OF THE NET and I don't want to come over to YOUR SIDE OF THE NET. Sometimes I feel like we're on OPPOSITE TEAMS. (F, 30. married $11 / 2$ yrs)

Actually, this woman could be structuring her concept of conflict with any number of metaphoric concepts that involve opposing teams on either side of a net, including 
badminton and doubles ping-pong. The conceptual metaphor she was using to structure her concept of conflict was rooted in her own personal experience, and as the researcher, I can only speculate as to what her experience may be without further knowledge of the respondent's life history.

Concluding this chapter's description of structural metaphors, two men and two women structured the concept of marital conflict through the metaphoric concept of a performance. Their satellite metaphors were the manifestation of the structural metaphor CONFLICT IS A PERFORMANCE:

I PLAYED IT UP.... My husband happens to be the SOUNDING BOARD.... I'm DR. JEKYLL AND MR. HYDE. ... IT WAS A PLAY.... I was EGGING him into a conflict, wanting him to say something. ... I was doing it for the SHOCK VALUE. ... I was also aware that PEOPLE WERE LAUGHING, almost EGGING ME ON... . I tend to GO ON LONGER than is necessary. (F, 38, married $11 \mathrm{yrs)}$

My GESTURES become emphatic. THE MAESTRO COMES OUT! . . . IN THE COMICAL VERSION, I'd like to lay a real big kiss on her RIGHT IN THE MIDDLE OF IT. (M, 31, married 1 1/2 yrs)

I REHEARSE WHAT I'M GOING TO SAY WHEN I GET OUT THERE. I take a little time to go through it. I know that I'm GOING ON.... I help her to step back and TAKE IN THE BIG PICTURE. (M, 32 , married 2 yrs)

This man's spouse also metaphorically structured conflict as a performance:

That would have helped SET THE STAGE for a more productive argument.... He wants to leave the SCENE immediately. (F, 28, married 2 yrs)

Overall, two of the men and two of the women structured marital conflict metaphorically as a performance. Two of these respondents used this metaphor as a couple. 
Ontological Metaphors and Their Satellites

While structural metaphors organize one concept in terms of another, ontological metaphors organize a concept in terms of an entity or substance. I have identified the respondents' ontological metaphors to be:

1. CONFLICT IS A BOMB

2. CONFLICT IS A PUZZLE

3. CONFLICT IS A BARRIER

4. CONFLICT IS A CONTAINER

The ontological metaphor CONFLICT IS A BOMB organizes the concept of conflict in terms of an entity, a bomb. With a clap of his hands, one respondent imitated a bomb: "She just 'BAM!'. He continued, "It will SET HER OFF and FUEL THE FIRE" (M, 32, married 2 yrs). A second respondent explained, "My TEMPER IS REALLY SHORT.... It's the ultimate rational male meeting with 'Italianism'! KABOOM!" (M, 31, married 11/2 yrs). A third man exclaimed, "It can really SET ME OFF!" (M, 31, married 8 1/2 yrs), and his wife stated, "I can EXPLODE at the snap of a finger.... I knew when he came home that it was going to be a BLOW UP. We were both real tense and then everything FLARES" (F, 32, married $81 / 2$ yrs). Another woman created satellite metaphors referring to bombs and fuses as well:

I tend to let things FUSE quicker. I will let things BLOW UP. The fact that the dishes didn't get done was the FUSE, and I EXPLODED. (F, 38 , married 11 yrs) 
Overall, three of the men and two of the women organized their concept of marital conflict according to the properties of a bomb. Only one couple used this ontological metaphor as a team.

A second ontological metaphor respondents used to organize the concepts of conflict was CONFLICT IS A PUZZLE:

She can feel inadequate about not being able to SOLVE THE PROBLEM. ... We don't go to bed without the PROBLEM being SOLVED.... I want to SOLVE the conflict. Be quiet and it will be SOLVED.... We're already CLOSER TO A SOLUTION. ... I would give anything to be able to SOLVE IT. I can be so interested in TRYING TO SOLVE THE PROBLEM that I can miss what she is saying. ... The PROBLEM is cyclical... I I was trying to SOLVE a new conflict.... We SOLVED IT, and THE SOLUTION CAME TO US before we were going to bed. ... She thought her SOLUTION was acceptable.... I wasn't going to PUT THOSE PIECES OF LOGIC TOGETHER. (M, 31, married 1 1/2 yrs)

At one point during the interview, this man's spouse also organized her concept of conflict as a labyrinth or puzzle:

It's a CHALLENGE to have it ALL COME OUT RIGHT at the right time. (F, 30, married 1 1/2 yrs)

Other references to the ontological metaphor CONFLICT IS A PUZZLE were:

I was TRYING TO FIGURE OUT what the PROBLEM was. (M, 31, married $81 / 2$ yrs)

THE PROBLEM GETS SOLVED. ( $F, 28$, married 2 yrs)

Overall, two men and two women created satellite metaphors referring to the ontological metaphor CONFLICT IS A PUZZLE. Two of these respondents used it as a couple. 
An addition, I inferred the ontological metaphor CONFLICT IS A BARRIER to be popular with respondents in this study:

I'm seeing it from THE OTHER SIDE.... He was doing everything he could to TEAR [the conflict] DOWN. (F, 28, married 2 yrs)

Her spouse offered:

I guess I just kind of PUT UP A WALL, really. (M, 32, married 2 yrs)

A woman in another couple explained:

We don't like to feel like there is this WALL BETWEEN US. . . . I wish I didn't feel the need to create extra space for myself, to GET INTO MY OWN PERSONAL SPACE, to protect myself. The physical distance is necessary, because INSIDE I'M TRYING TO PROTECT MYSELF. (F, 30 , married $11 / 2$ yrs)

Her husband also organized his concept of conflict as a barrier:

Having such a GULF OF DISTANCE BETWEEN YOU can be very painful.... I BURST THROUGH [conflict]. (M, 31, married 1 1/2 yrs)

Two other men inferred the ontological metaphor CONFLICT IS A BARRIER as well:

It's SET IS CONCRETE already.... We are CHIPPING AWAY AT IT. ... I want her to be able to see MY SIDE of the [conflict], and she can't seem to be able to SEE IT FROM MY SIDE. ... WE'LL GET

AROUND THIS some way. (M, 40, married 11 yrs)

There is clearly a distance BETWEEN US. ... You CAN'T GET PAST [the conflict]. (M, 31, married $81 / 2 \mathrm{yrs})$

Overall, all four men and two of the women employed the metaphoric concept CONFLICT IS A BARRIER. Four of these respondents formed two couples that organized their concepts of marital conflict in this manner. 
A fourth metaphoric concept, CONFLICT IS A CONTAINER, was used by three out of four couples in this study. Seven out of all eight respondents' used satellite metaphors referring to being IN or OUT of conflict, like being IN a bucket or OUT of a box:

I would like to not BRING THAT ERROR INTO [CONFLICT], just LEAVE THOSE THINGS OUT OF IT. ... We just WENT INTO a verbal battle ... (F, 28, married 2 yrs)

Her husband created more satellite metaphors for the ontological metaphor

CONFLICT IS A CONTAINER than any other respondent:

I just want to EASE ON INTO the moment ... and see WHO COMES

OUT the winner. ... I always GET THE LAST WORD IN.... we find ourselves IN the same [conflict] . . . When I GET INTO a certain [conflict], I know that I'M GOING IN.... She doesn't want to be IN THE CONFLICT SITUATION either.... We're two people IN CONFLICT who don't want to be there.... It takes me a while to GET INTO IT. ... I try to derive as much meaning as I can OUT OF EACH CONFLICT situation. ( $\mathrm{M}, 32$, married $2 \mathrm{yrs}$ )

In the car, we GET INTO little conflicts.... It's a challenge to have EVERYTHING ALL COME OUT RIGHT at the right time.... If we GET INTO an argument, it will start as a teasing thing and then somehow TWIST INTO a problem. (F, 30, married $11 / 2 \mathrm{yrs}$ )

This woman's spouse also organized his concept of conflict according to the entity of a container:

When we're IN THE MIDDLE OF [conflict], I can GET INTO IT. . . . Sometimes when you GET INTO A CONFLICT, ... She was trying to COERCE ME INTO [conflict]. (M, 31, married 1 1/2 yrs)

A third couple also used the ontological metaphor CONFLICT IS A CONTAINER to organize their concepts of marital conflict: 
Then I'll STEP IN and say .... I didn't want to FALL INTO IT. ... He does not want to get involved IN CONFLICT.... I have to do something to channel my anger INTO SOMETHING ELSE. . . I was almost egging him INTO A CONFLICT. ... If we're IN AN ARGUMENT, . . (F, 38, married 11 yrs)

Her spouse stated:

There's a leader INTO THESE CONFLICTS. ... You GET INTO these patterns of conflict about different issues.... her job LEADS US INTO [conflict].... I try to ease her frustration OUT OF THE CONFLICT.... Let's not keep BARRELING INTO THIS PROBLEM. (M, 40, married 11 yrs)

Finally, a fourth man implied the container metaphor:

You are just so emotionally TIED UP IN IT that you can't ... I was trying to TALK THINGS OUT, REASON THINGS OUT. (M, 31, married 8 $1 / 2 \mathrm{yrs})$

Overall, all four men and three of the women, forming three out of the four couples, used the ontological metaphor CONFLICT IS A CONTAINER. The metaphoric concept of CONFLICT IS A CONTAINER is also closely tied to the orientational metaphor CONFLICT IS IN; NON-CONFLICT IS OUT to be discussed in the following section on orientational metaphors and their satellites.

\section{Orientational Metaphors and Their Satellites}

As well as structural and ontological metaphors, I inferred from the respondents' discourse that all of the respondents used orientational metaphors to organize their concepts of marital conflict. Based in our physical and cultural experience, most orientational metaphors "... have to do with spatial orientation: up-down, in-out, front-back, on-off, deep-shallow, central-peripheral," (Lakoff \& 
Johnson 1980, p. 14). Orientational metaphors are metaphoric concepts that organize concepts with respect to one another, and in doing so, contribute to the complexity of conceptual metaphors by serving as preludes and modifications to structural and ontological, as well as other orientational, metaphors. It is my interpretation that the respondents in this study collectively used over three hundred satellite metaphors referring to a variety of orientational metaphors. The following is a list of the orientational metaphors respondents revealed in this study. Each orientational metaphor is followed by a sampling of its observable satellite metaphors.

The most typical orientation for the concept of conflict that respondents used in this study was the orientational metaphor CONFLICT IS UP; NON-CONFLICT IS DOWN. Every respondent employed it, and the CONFLICT IS UP; NON-CONFLICT IS DOWN orientational concept accounted for approximately twenty five percent of all of the orientational satellite metaphors I interpreted from the respondents' discourse. The following is a sampling of the satellite metaphors generated by respondents:

\section{CONFLICT IS UP; NON-CONFLICT IS DOWN}

Conflict may not go to the same HEIGHT, but ... the next time that conflict comes UP we'll . . until I can WIND DOWN. (M, 31, married 1 $1 / 2 \mathrm{yrs})$

I will bring UP things to him.... [conflict] will come UP ... I I was being very sure of myself, sort of 'I can TOP THIS'.... I could feel the pressure BUILDING AND BUILDING in my mind. I played it UP.... Then the conflict was just sort of DROPPED. (F, 38, married $11 \mathrm{yrs)}$ 
The next time [conflict] ARISES, I'll know ... Conflict situations ARISE at home... communication happens later when we both CALM DOWN.... [Conflict] ends by me just DROPPING IT.... It DRAINS me of energy to continue. ( $\mathrm{M}, 32$, married $2 \mathrm{yrs}$ )

I'll bring it UP.... and I'll DREDGE UP everything that's been bugging me for a week. (F, 28, married 2 yrs)

As indicated by the presence of satellite metaphors, the opposite orientation was also used by all of the respondents, though not nearly as frequently:

\section{CONFLICT IS DOWN; NON-CONFLICT IS UP}

I didn't want to FALL into [conflict]. ... DEEP DOWN I was trying to be hurtful (F, 38, married 11 yrs)

I give UP! ... Once you go DOWN the path [of conflict] ... (M, 32, married 2 yrs)

We get DOWN to arguing.... It all comes DOWN to how we deal with the facts.... It hasn't been so difficult for me to give UP. (M, 31, married $11 / 2$ yrs)

The second most typical orientation for the concept of conflict in this study was CONFLICT IS IN; NON-CONFLICT IS OUT. Seven out of eight respondents used this orientation, and it accounted for approximately twenty percent of all of the orientational satellite metaphors. As noted earlier, all of the satellite metaphors representing the ontological metaphor CONFLICT IS A CONTAINER are also satellite metaphors indicating the operation of the orientational metaphoric concept CONFLICT IS IN; NON-CONFLICT IS OUT:

CONFLICT IS IN; NON-CONFLICT IS OUT

It will START OUT a teasing thing, and then somehow TWIST INTO a problem.... We will get INTO little conflicts. (F, 30, married $11 / 2 \mathrm{yrs}$ ) 
You are just so tied up IN IT that you can't. ... reasonably WORK THINGS OUT. (M, 31, married $81 / 2$ yrs)

Her job leads us INTO [conflict].... We GET INTO patterns of [conflict]... and I feel WRUNG OUT.... Let's not keep barreling INTO this. (M, 40, married $11 \mathrm{yrs)}$

The opposite orientation was used by only three respondents, one couple and a second man:

\section{CONFLICT IS OUT; NON-CONFLICT IS IN}

The two of us were clearly PUT OUT about something.... I usually come right OUT and tell her ... it comes OUT in different ways.... The first things OUT of her mouth were ... (M, 31, married $81 / 2 \mathrm{yrs})$

Then I have to pull it all IN and think. ... the feelings are really coming OUT. I'm not holding as much IN.... He couldn't spit anything else OUT. (F, 32, married $81 / 2$ yrs)

When I hear negative comments come OUT of her mouth .... Sometimes just getting it OUT IN THE OPEN helps.... My gestures become emphatic, the maestro comes OUT.... Just let her get it OUT. (M, 31, married 1 1/2 yrs)

A third orientational concept for marital conflict used by all respondents in this study was CONFLICT IS FRONT; NON-CONFLICT IS BACK. The following sample of satellite metaphors I have interpreted to be representative of the orientation CONFLICT IS FRONT; NON-CONFLICT IS BACK might also be interpreted as representative of the previously explored structural metaphor CONFLICT IS WAR:

\section{CONFLICT IS FRONT; NON-CONFLICT IS BACK}

If I'm the one who's challenging, I'll tend to move FORWARD. If I'm being challenged, I pull BACK. ... We'll go BACK to being status quo. (M, 31, married 11/2 yrs) 
[During conflict], I'm not one to hold BACK. (F, 28, married $2 \mathrm{yrs)}$

I get tense and often feel a sense of WITHDRAWAL .... I would back away from [conflict].... I try to pull BACK. (F, 30, married 11/2 yrs)

Once you [conflict], there's no turning BACK.... I help her to relax and take a step BACK. . (M, 32, married 2 yrs)

He tried to take BACK his remarks.... he knows when to BACK off. ... I try to be very up FRONT with him. (F, 38, married 11 yrs)

We'll go BACK AND FORTH. We went BACK AND FORTH for ten minutes. (M, 31, married $81 / 2 \mathrm{yrs}$ )

Let's put it BEHIND US. (F, 32, married $81 / 2 \mathrm{yrs)}$

Only two respondents, husband and wife, used the opposite orientational metaphor:

\section{CONFLICT IS BACK; NON-CONFLICT IS FRONT}

He'll be defensive BACK because he's been attacked. (F, 28, married 2 yrs)

Sometimes we still REVERT BACK to long [conflict]. (M, 32, married 2 yrs)

All of the respondents used the orientational concept CONFLICT IS CLOSE; NON-CONFLICT IS FAR:

CONFLICT IS CLOSE; NON-CONFLICT IS FAR

It's the ultimate rational male MEETING WITH Italianism. Kaboom! . . . The conflict CAME up last week. It CAME before we were going to bed. (M, 31, married 1 1/2 yrs)

Conflict doesn't COME up very often.... Sometimes he COMES down too hard. . . I want him to REACH FOR A COMPROMISE. ... Stupid arguments COME when we're having fun. ... I wish I wouldn't LET THINGS GET TO ME. (F, 30, married $11 / 2 \mathrm{yrs)}$ 
If I've been hurt, I can't LET IT GO. ... He'll REACH A POINT where he's LEAVING IT alone. (F, 38, married 11 yrs)

Eventually the conflict just FADES AWAY.... Once [conflict]

PASSES, I let it GO and it's GONE. (M, 40, married 11 yrs)

Seven out of eight respondents used the opposite orientation, though much less frequently:

\section{CONFLICT IS FAR; NON-CONFLICT IS CLOSE}

We get CLOSER AND CLOSER TO RESOLVING things.... We come TOGETHER with agreement. (M, 40, married $11 \mathrm{yrs)}$

As time goes on, she does take ONE STEP CLOSER to where I am, or I take ONE STEP CLOSER to where she is (a resolution).... The solution CAME TO US before we went to bed. (M, 31, married 11/2 yrs)

Three out of the eight respondents, one couple and a second woman, spatially oriented conflict as either being ON or OFF:

\section{CONFLICT IS ON; NON-CONFLICT IS OFF}

We don't know what's going ON.... We'll be ON opposite sides.... I try to keep [conflict] ON a rational level.... KNOCK IT OFF! (M, 31, married $81 / 2$ yrs)

I'll take you ON!... I I used to shut OFF... He backed OFF. (F, 32, married $81 / 2$ yrs)

I went ON AND ON about it.... I just have to pick ON somebody... I I will brush him OFF.... He knows to back OFF.... I tend to go ON longer than necessary. (F, 38, married $11 \mathrm{yrs}$ )

Three out of the four men used the opposite orientation:

CONFLICT IS OFF; NON-CONFLICT IS ON 
It really sets me OFF! ... The other one is just waiting to take their head OFF. (M, 31, married $81 / 2$ yrs)

We solved it ON two contingencies. (M, 31, married 11/2 yrs)

I argue OFF the top of my head. (M, 40, married $11 \mathrm{yrs)}$

Three men also conceptually oriented conflict as CONFLICT IS OVER; NON-CONFLICT IS UNDER:

CONFLICT IS OVER; NON-CONFLICT IS UNDER

Conflict came up OVER dinner. (M, 31, married $11 / 2 \mathrm{yrs)}$

It's the same conflict OVER AND OVER. (M, 32, married 2 yrs)

We get mad and [conflict] OVER something. (M, 31, married $81 / 2 \mathrm{yrs)}$

Finally, two men used the orientational concept of CONFLICT IS PERIPHERAL; NON-CONFLICT IS CENTERED:

CONFLICT IS PERIPHERAL; NON-CONFLICT IS CENTERED

It always begins with [conflict] that REVOLVES AROUND my pride. (M, 31, married 11/2 yrs)

[I try to] come to a MIDDLE ground, a COMPROMISE situation. (M, 40 , married $11 \mathrm{yrs}$ )

In addition, all respondents frequently juxtaposed a variety of these

orientational metaphors to create orientational combinations for the concept of conflict. The following are a few examples:

I didn't want to FALL INTO [conflict]. ... I am very UP FRONT with him.... [conflict] will COME UP ... He knows when to BACK OFF. (F, 38, married $11 \mathrm{yrs}$ )

[Conflict] COMES OUT IN different ways. (M, 31, married 8 1/2 yrs) 
Conflict COMES UP IN the car.... [conflict] COMES DOWN to how we deal with the facts.... [Conflict] CAME UP OVER dinner. (M, 31, married $11 / 2$ yrs)

He BACKED OFF.... The feelings are really COMING OUT. (F, 32, married $81 / 2$ yrs)

I feel like he COMES DOWN too hard. ... Conflict doesn't COME UP very often. ( $F, 30$, married $11 / 2$ yrs)

Upon analyzing the transcripts of the respondents' discourse, I inferred that each respondent in this study used structural, ontological, and orientational metaphoric concepts to organize his or her personal concepts of marital conflict. Following is the second section of Chapter IV, ANALYSIS, which will focus on the analysis of the data collected in this study, and attempt to identify patterns in respondents' use of conceptual metaphor.

ANALYSIS

As respondents answered questions posed from the interview schedule, they usually responded thoughtfully. I examined and interpreted the respondents' discourse, and inferred some patterns among the respondents' use of structural, ontological and orientational metaphor. ANALYSIS will discuss my interpretations of the data and explore the inferred patterns of respondents' use of conceptual metaphor.

Upon analyzing the respondents' discourse describing their experiences in marital conflict, it is my interpretation that all eight respondents created satellite metaphors referring to the metaphoric concept CONFLICT IS COMPETITION. 
Seven of these respondents' satellite metaphors specifically reflected the structural metaphor CONFLICT IS WAR. MY inference of the respondents' uniform structuring of conflict in terms of COMPETITION, and specifically WAR, leads me to suggest a relationship between the structural metaphors CONFLICT IS COMPETITION and CONFLICT IS WAR for the respondents in this study.

Further, from the respondents' discourse, I inferred that all of the respondents who structured their concepts of marital conflict as CONFLICT IS COMPETITION, and specifically WAR, also referred to the orientational concepts of CONFLICT IS FRONT; NON-CONFLICT IS BACK as well as CONFLICT IS CLOSE; NON-CONFLICT IS FAR. This inferred pattern in the data leads me to suggest that, for the respondents in this study, a relationship exists between the metaphoric concept of CONFLICT IS COMPETITION/WAR and the metaphoric spatial orientation of conflict being up FRONT and CLOSE while non-conflict is BACK and FAR AWAY. (Possibly hand to hand combat takes place on the FRONT lines and CLOSE to the enemy, while non-conflict is characterized by retreat, BACK and FAR.)

To continue, I interpreted from the respondents' discourse that the respondents who conceptualized their marital conflict in terms of CONFLICT IS WAR also created satellite metaphors that referred to the ontological metaphor CONFLICT IS A CONTAINER. The inferred pattern leads me to suggest that, for the respondents in this study, a relationship exists between their metaphoric structuring of marital conflict as CONFLICT IS WAR and their organizing of 
marital conflict according to the ontological metaphor CONFLICT IS A

\section{CONTAINER.}

Continuing to analyze the data, I realized that my interpretation of a respondent's discourse, and my inference of the respondent's structural, ontological, or orientational metaphors used throughout his or her discourse, did not necessarily indicate the significance of a metaphoric concept to that respondent. Further, the number of times a satellite metaphor was used, or not used by a respondent, did not necessarily reflect upon the significance of the implied conceptual metaphor for the respondent. For example, a respondent's frequent use of a certain satellite metaphor referring to an orientational concept may be habitual or culturally commonplace, and therefore, carry less meaning for that respondent than would the singular use of an original satellite metaphor referring to a unique metaphoric concept:

... metaphors that are outside our conventional conceptual system, metaphors that are imaginative and creative ... are capable of giving us a new understanding of our experience. Thus, they can give new meaning to our pasts, to our daily activity, and to what we know and believe. (Lakoff \& Johnson, 1980, p. 139)

As analysis progressed, I inferred additional patterns from the data. I interpreted that the discourse of four respondents individually contained more satellite metaphors implying structural metaphors than the discourse of the other respondents. These four respondents were also the only four from whose discourse I inferred the structural metaphor CONFLICT IS A PERFORMANCE. My interpretation of the four respondents' metaphoric structuring of CONFLICT IS A 
PERFORMANCE, along with the same four respondents' tendency to use satellite metaphors referring to structural metaphors in general, leads me to suggest a relationship, for these four, between their structuring of marital conflict as CONFLICT IS A PERFORMANCE and their tendency to use satellite metaphors referring to structural metaphors in general.

Analysis of the respondents' use of orientational metaphors also lead me to infer a few patterns in the data. For example, the only couple (hereafter referred to as COUPLE A) from whose discourse I inferred the structural metaphor CONFLICT IS A PERFORMANCE, was also the only couple (as well as the only two respondents) from whose discourse I inferred the orientational metaphor CONFLICT IS BACK; NON-CONFLICT IS FRONT. From all of the respondents' discourse however, I inferred the opposite orientational metaphor, CONFLICT IS FRONT; NON-CONFLICT IS BACK. My interpretation of this data leads me to suggest that, for COUPLE A, a relationship may exist between the conceptualization of CONFLICT IS PERFORMANCE and the spatial orientation of CONFLICT IS BACK; NON-CONFLICT IS FRONT. (Possibly, marital conflict may be appropriate BACK stage, yet not in FRONT of the audience.)

My interpretations of the data further suggest that the only couple (hereafter referred to as COUPLE B) from whose discourse I inferred the ontological metaphor CONFLICT IS A BOMB, was also the only couple from whose discourse I inferred the orientational metaphor CONFLICT IS OUT; NON-CONFLICT IS IN. Once again, however, I more frequently inferred the opposite orientation, 
CONFLICT IS IN; NON-CONFLICT IS OUT from the discourse of the respondents in this study. My interpretation of this data leads me to suggest a relationship, for the respondents in COUPLE B, between the ontological concept CONFLICT IS A BOMB and the orientational concept CONFLICT IS OUT; NON-CONFLICT IS IN. (Possibly, to explode like a bomb is to throw energy and fragments OUT, and to stifle a bomb is to contain the energy and hold the fragments IN.)

Further analysis lead me to infer that COUPLE B was also the only couple to orient the concept of marital conflict as CONFLICT IS ON; NON-CONFLICT IS OFF. I inferred COUPLE B's use of the ON/OFF orientation to be inconsistent with their use of the ontological conceptualization of CONFLICT IS A BOMB. It is my interpretation that when conflict is a BOMB, exploding energy and fragments OUT, the BOMB is commonly said to go "OFF", not "ON". HOWEVER, coherent with the concept of CONFLICT IS A BOMB, is the concept of a bomb needing to be activated, or turned "ON" in order to be effective. According to Lakoff \& Johnson (1980), there is a "crucial" difference between metaphoric concepts that are "consistent", and metaphoric concepts that are "coherent". Lakoff and Johnson explain:

Although the two metaphors are not consistent (that is they form no single image), they nonetheless "fit together," by virtue of being subcategories of a major category and therefore sharing a major common entailment.... We have found that the connections between metaphors are more likely to involve coherence than consistency. (Lakoff \& Johnson, 1980, p. 44) 
My interpretation of inconsistency between the orientational metaphor CONFLICT IS ON; NON-CONFLICT IS OFF and the ontological metaphor CONFLICT IS A BOMB is rooted in my own physical and cultural experience. When I first became interested in the metaphoric language that people used to describe conflict, I heard the satellite metaphor "She'll usually DANCE AROUND the issue," and assumed that this satellite metaphor referred to the metaphoric concept CONFLICT IS A DANCE. To my surprise, I was informed that this satellite metaphor was more commonly used by others in reference to the metaphoric concept CONFLICT IS A BOXING MATCH. My physical and cultural experiences had little to do with boxing and much more of a relationship with dancing. It was meaningful, and therefore natural, for me to understand "DANCING AROUND the issue" as a reflection of the conceptual metaphor CONFLICT IS A DANCE.

Similarly, during the first pre-test for the interview schedule, while describing marital conflict, the respondent used the satellite metaphor "I usually FLY OFF THE HANDLE." Based on my life experience, I assumed the respondent was structuring marital conflict according to the concept of cooking, having her hand FLY OFF a hot pot HANDLE. The next day, however, I was informed that the "FLY OFF THE HANDLE" satellite metaphor might actually refer to the concept of chopping wood, where the ax head could FLY OFF THE HANDLE, out of control. If the pre-test respondent's physical and cultural life experiences were similar to mine, she may have been referring to the metaphoric concept CONFLICT 
IS COOKING. A satellite metaphor implies whatever conceptual metaphor the user understands it to imply; and not necessarily the conceptual metaphor inferred by someone else.

Finally, my analysis of the respondents' discourse lead me to infer that two of the eight respondents (hereafter referred to as Cindy and Debra) never used to the same structural or ontological metaphors to organize their concepts of marital conflict. My interpretation of Cindy's discourse suggested that she organized her concept of marital conflict according to the metaphoric concepts CONFLICT IS A JOURNEY, CONFLICT IS A PUZZLE, CONFLICT IS A BARRIER, and CONFLICT IS A CONTAINER.

On the other hand, my interpretation of Debra's discourse suggested that she organized her concept of marital conflict according to the metaphoric concepts CONFLICT IS BOXING, CONFLICT IS A VOLCANIC ERUPTION, and CONFLICT IS A BOMB. My interpretations lead me to infer that the metaphoric concepts organizing Cindy's concept of marital conflict were a "gentler" collection than the "violent" metaphoric concepts organizing Debra's concept of marital conflict. From the conceptual metaphors we employ, we infer an organization for our perception of reality, creating meaning for, and affecting our reaction to, our perception of reality. The following chapter, Chapter V, Conclusions, will discuss the implications this study may have for marital conflict management. The strengths and limitations of this study will also be presented, along with suggested directions for future research. 


\section{CHAPTER V}

\section{CONCLUSIONS}

\section{INTRODUCTION}

In this chapter, I suggest the practical implications this study may have in the area of marital conflict management. I also present the limitations of this study, and follow with a discussion of the benefits of naturalistic research methods. Finally, I discuss directions for future research.

\section{IMPLICATIONS}

Current theory proposes that whether a conflict is a productive or a destructive process depends on how the conflict is managed. Learning more about conflict management will enhance our understanding of conflict resolution, and this knowledge can be applied to ensure that conflict be a productive interpersonal communication process.

Specifically, the consistency of language based on the assumption that language influences behavior seems to suggest that married couples, professionals involved in the counseling of married couples, and all those who study marital conflict resolution, can benefit from further understanding the conceptual metaphors of marital conflict (see Suggested Directions for Future Research). 


\section{LIMITATIONS OF THIS STUDY}

The ability to conduct an informative interview is an acquired skill. In this study, the researcher's lack of prior experience in conducting such interviews may have been a shortcoming. The transcripts revealed that occasionally respondents' statements were not fully elaborated, and that further probing and follow up questions may have been beneficial. Each respondent participated in one interview session, and in the interest of gathering a truly complete set of data, a second session with each respondent would have been helpful. A second interview would have allowed the interviewer to review a first set of transcripts in order to identify statements requiring further attention.

A second interview session with each respondent would also have given the interviewer an opportunity to clarify, or verify the respondents' use of conceptual metaphor. Reviewing the transcripts, the researcher identified the respondents' use of metaphoric concepts through her own physical and cultural experience. Therefore, there is always the possibility that the respondents were not using the conceptual metaphors that the researcher inferred they were using.

A second interview with each respondent could have been divided into two sections. The first section could have been used for further elaboration, and the second section could have been used for metaphor verification. 


\section{BENEFITS OF USING NATURALISTIC RESEARCH METHODS}

All of the respondents seemed willing to share personal information about their marriages and their marital conflicts. After the interviews, several respondents said that they "enjoyed our conversation", that they had talked about their marriages from perspectives they had never considered before, and that discussing their experiences with marital conflict may have helped them to "realize a few new options" in conflict management. All of the respondents requested a copy of the completed study in order to review the results and "find out what's happening in my marriage." These comments suggest that the respondents were eager to learn about the functioning of their marriages, interested in conflict management, and open to positive change.

\section{SUGGESTED DIRECTIONS FOR FUTURE RESEARCH}

When two people conflict, each will opt for an assortment of conflict management behaviors. As well as the psychological framework that includes the metaphoric concept of conflict from which they are operating, an individual's conflict management behavior involves verbal and nonverbal tactics strategically used to resolve the conflict. Those who argue that conflict resolution strategy is predetermined by personal characteristics would expect an individual to use same resolution strategy in different conflict situations. Those who argue that conflict resolution strategy is predetermined by situational characteristics would expect an individual to vary their resolution strategy in different situations. 
Several researchers view conflict resolution strategy to be a stable aspect of individual personality, which will be adopted regardless of the situation (Bell \& Blakeny, 1977; Brown, Yelsma, \& Keller, 1981; Jones \& Melcher, 1982; Terhune, 1970). Kilmann and Thomas (1975) investigated the Jungian psychological correlates of an individual's choice of five different conflict management modes. Thomas (1976) proposed that individuals possess a hierarchy of responses to conflict, the dominant response, or strategy, being shaped by motives and abilities. If the dominant response fails to work, then other responses may be tried:

This is not to say that [the individual] has inflexible traits and that his behavior does not vary from situation. Rather, [the individual] is assumed to have some tendencies in his behavior, (Thomas, 1976, p. 913).

Lawrence and Lorsch noted:

Managers in all the organizations we studied almost unanimously saw confrontation as the most desirable mode of conflict resolution. Yet our findings indicate it is used much less than it is recommended. This is most commonly explained by the assumption that people have the requisite knowledge, but have a personality-based aversion to confronting differences sharply. (1967, p. 222)

Other researchers propose that conflict resolution strategy is contingent upon the situation, and that people are able to choose different approaches in different contexts. Folger and Poole (1984) define resolution strategies as "orientations" people can take toward conflict that include general expectations of how conflict should be managed. "... choosing an orientation is making a decision about the principles that will guide one through the conflict; it is choosing the degree to which parties will be cooperative and $\backslash$ or assertive," (Folger \& Poole, 1984, p. 44). Studies that reject the personality-trait model of conflict resolution strategy focus on the 
effectiveness of the conflict management behavior in a given situation rather than on the individual's personal style of behavior, (Burke, 1970; Lawrence \& Lorsch, 1967). These studies introduce the concept of choice of conflict strategy and behavior as opposed to predisposition, and evaluate the use of particular choices in various situations.

Additional studies have explored the effectiveness of conflict resolution strategies in various situations (Burke, 1970; Derr, 1978; Hocker \& Wilmot, 1985; Phillips \& Cheston, 1979; Rahim, 1983, 1985; Renwick, 1975; Robbins, 1978; Thomas, et al, 1978). Collectively, these studies conclude that specific resolution strategies are most appropriate in conflict situations that possess certain characteristics. These studies also suggest that situational characteristics can indicate which resolution strategy may be most appropriate in a given conflict situation.

Several researchers have created instruments to measure and categorize a person's choice of conflict resolution strategy, (Kilmann \& Thomas, 1975; Lawrence \& Lorsch, 1967; Rahim, 1983). Putnam and Wilson (1982) developed the Organizational Communication Conflict Instrument (OCCI) to measure the use of conflict management strategies in a variety of characteristically defined conflict situations. The long-range goal of their research is to identify factors that affect decisions to use particular strategies, and to test the evolution of these strategies across conflict episodes. 
The extent to which an individual uses a particular conflict management behavior can be interpreted as a repertoire of specialized skills. "The fact remains that individuals are good at different things, and that almost any behavior can constitute a skill in an appropriate situation," (Thomas, 1977, p. 489). If a person's ability to resolve conflict can be said to be dependent upon the compatibility between his or her conflict management behavior and the characteristics of a conflict situation, then being able to understand how one's use of conceptual metaphor affects their choice of conflict management behavior would help them to assess the degree of compatibility between the conflict situation and their preferred conflict management behavior. By identifying the characteristics of a conflict situation, particularly a potentially advantageous or difficult situation for the individual's skill level, a participant could choose to alter his or her metaphoric concept of conflict and adjust behavior, or identify and seek out similar or different, more favorable conflict situations in the future.

Those who wish to continue inquiry along these lines might be guided by questions such as the following:

1. To what extent does a relationship exist between the conceptual metaphor(s) an individual uses to organize his/her concept of marital conflict and the situational characteristics of a given marital conflict?

2. To what extent does a relationship exist between the conceptual metaphor(s) an individual uses to organize his/her concept of marital conflict and the individual's use of conflict resolution strategy(ies)? 
3. Which conflict resolution strategies do respondents perceive to be most effective in marital conflict management?

4. To what extent does a relationship exist between the conceptual metaphor(s) an individual uses to organize his/her concept of marital conflict and the gender of the individual?

5. To what extent does a relationship exist between the conceptual metaphor(s) an individual uses to organize his/her concept of marital conflict and the individual's profession or livelihood?

6. Which conceptual metaphors do respondents perceive to be most effective toward marital conflict resolution?

Overall, more extensive and rigorous testing, either observational or using independent measures of conflict management behavior, may enable future researchers to explore whether the linguistic patterns identified in this study can be observed in actual behavior. 


\section{REFERENCES}

Bell, E.C., and Blakeny, R.N. (1977). Personality correlates of conflict resolution modes. Human Relations, 30, 849-857.

Bogdan, Robert, and Taylor, Steven J. (1984). Introduction to qualitative research methods: The search for meanings. New York, NY: John Wiley and Sons, Inc.

Brown, C.T., Yelsma, P., and Keller, P.W. (1981). Communication- conflict predisposition: Development of a theory and an instrument. Human Relations, 34, 1103-1117.

Burke, R.J. (1970). Methods of resolving superior-subordinate conflict: The constructive use of subordinate differences and disagreements. Organizational Behavior and Human Performance, 5, 393-411.

Derr, B. (1978). Managing organizational conflict. California Management Review, 21, 76-83.

Fainsilber, Lynn, and Ortony, Andrew (1987). Metaphorical uses of language in the expression of emotions. Metaphor and Symbolic Activity, 2(4), 239-250.

Fitzpatrick, M.A. (1988). Between husbands and wives: Communication in marriage. Newbury Park, CA: Sage Publications, Inc.

Folger, J.P., and Poole, M.S. (1984). Working through conflict. Glenview, IL: Scott Foresman and Co.

Gibbs, Jr., Raymond W., and Gerrig, Richard J. (1989). How context makes metaphor comprehension seem "special". Metaphor And Symbolic Activity, 4(3), 145-158.

Glucksberg, Sam (1989). Metaphors in conversation: How are they understood? Why are they used? Metaphor and Symbolic Activity, 4(3), 125-143.

Hocker, J.H., and Wilmot, W.W. (1985). Interpersonal conflict. Iowa: Wm. C. Brown.

Jones, R.E., and Melcher, B.H. (1982). Personality and the preference for modes of conflict resolution. Human Relations, 35, 649-658.

Kilmann, R.H., and Thomas, K.W. (1975). Interpersonal conflict- handling behavior as reflections of Jungian personality dimensions. Psychological Reports, 37, 971-980. 
Lakoff, G., and Johnson, M. (1980). Metaphors we live by. Chicago, IL: University of Chicago Press.

Lakoff, G., and Turner, M. (1989). More than cool reason. Chicago, IL: University of Chicago Press.

Lawrence, P.R., and Lorsch, J.W. (1967). Organization and environment. Boston: Harvard University, Graduate School of Business Administration.

Levin, S.R. (1988). Metaphoric worlds: Conceptions of a romantic nature. New Haven, CT: Yale University Press.

Lofland, J. and Lofland, L. (1984). Analyzing social settings: A guide to qualitative observation and analysis. Belmont, CA: Wadsworth Publishing Company.

MacCormac, Earl R. (1985). A Cognitive Theory of Metaphor. Cambridge, Mass.: The MIT Press.

McCracken, Grant (1988). The Long Interview. Newbury Park, CA: SAGE Publications, Inc.

Phillips, E., and Cheston, R. (1979). Conflict resolution: What works? California Management Review, 21, 76-83.

Putnam, L.L., and Wilson, C.E. (1982). Communicative strategies in organizational conflicts: Reliability and validity of a measurement scale. Communication Yearbook, 6, 629-652.

Rahim, M.A. (1983). A measure of styles of handling interpersonal conflicts. Academy of Management Journal, 26, 368-376.

Rahim, M.A. (1985). Referent role and styles of handling interpersonal conflict. Journal of Social Psychology, 126, 79-86.

Renwick, P.A. (1975). Impact of topic and source of disagreement on conflict management. Organizational Behavior and Human Performance, 14, 416-425.

Robbins, S.P. (1978). Conflict management and conflict resolution are not synonymous terms. California Management Review, 21, 67-75.

Terhune, K.W. (1970). The effects of personality in cooperation and conflict. In P. Swingle (Ed.), The structure of conflict (pp. 193-234). New York: Academic Press.

Thomas, K. W. (1976). Conflict and conflict management. In M. Dunnette (Ed.), Handbook of industrial and organizational psychology (pp. 889-935). Chicago, IL: Rand McNally.

Thomas, K.W. (1977). Toward multi-dimensional values in teaching: The example of conflict behaviors. Academy of Management Review, 2, 484-490. 
Thomas, K. W., Jamieson, D. W., and Moore, R. K. (1978). Conflict and collaboration: Some concluding observations. California Management Review, 21, 91-95.

U.S. Bureau of the Census, Statistical Abstract of the United States: 1990 (110th edition.) Washington, DC, 1990, tables no. 131 and 133. 
APPENDIX A

INTERVIEW SCHEDULE 


\section{APPENDIX A \\ INTERVIEW SCHEDULE}

\section{INTRODUCTION}

First of all, I want to thank you for helping me with my study. It's important to me that you are comfortable with this interviewing process, so if you ever have a question, if you want something clarified, or if you would like to stop the interview, just let me know.

Before we actually begin the interview, I have one question: How long have you and your spouse been married?

I am going to ask you questions about typical conflict between you and your spouse, and then I will ask you about a recent conflict. The literature doesn't agree on an exact definition for the term "conflict", and for this study this is not a problem because I am interested in how YOU define and describe "conflict".

Are you ready to begin?

\section{BODY}

A. Typical Conflict

1. Topics Of Conflict

Tell me about some typical topics of [conflict] for the two of you. 
most frequent

most emotional

2. Settings Of Conflict

Tell me about a typical setting for [conflict] for you and your spouse.

where

social situations

events

frame of $\mathrm{mind} / \mathrm{mood}$

3. Process Of Conflict

Tell me about what happens during a typical [conflict] for you and your spouse.

begin

progress

end

What do you usually want out of a [conflict]?

4. Responses To Conflict

Tell me what happens inside of you during a [conflict] with your spouse.

feel

"I usually feel like . . ."

emotions

thoughts

physical reaction

5. Communication During Conflict 
Tell me about the sort of things you might say during [conflict].

phrases

words

Tell me what a fly on the wall might see you doing during [conflict].

gestures

facial expressions

bodily stance

What would you often like to do?

"I often wish I could . . . ."

B. Recent Conflict

1. Topic Of Recent Conflict

Tell me about the topic of your recent [conflict].

2. Setting Of Recent Conflict

Tell me about the setting for this [conflict].

location

event

social situation

frame of mind

3. Process Of Recent Conflict

Tell me what happened during this recent [conflict].

begin

end 
Tell me what you wanted out of this [conflict].

4. Responses To Recent Conflict

Tell me how you felt during this recent [conflict].

"I felt like. . . "

emotions

thoughts

physical reaction

5. Communication During Recent Conflict

Tell me about the things you said during this recent [conflict].

phrases

words

What behaviors would a little fly on the wall have seen if it were watching you?

gestures

bodily stance

facial

expressions

What do you wish you could have done?

6. Role Play of Recent Conflict

Pretend that you and your spouse are here . . . .

you said/did

you recall other said/did 


$$
\begin{aligned}
& \text { you wish you had said/did } \\
& \text { you wish you could say/do }
\end{aligned}
$$

\section{CONCLUSION}

Thank you. You've been great. Remember, all of this information will be confidential. If you would like, I can give you the results of this study when it is complete. Do you have any questions for me?

Thank you again. 
APPENDIX B

INFORMED CONSENT FORM 


\section{APPENDIX B}

\section{INFORMED CONSENT FORM}

I, , hereby agree to serve as a respondent in the research project investigating how people refer to marital conflict conducted by Anne Seger.

I understand that this study involves my verbally responding to open-ended questions asked by Anne Seger, and that my time commitment to this study will be less than an hour.

I may not receive any direct benefit from participation in this study, but my participation may help to increase knowledge which may benefit others in the future.

Anne Seger has offered to answer any questions I may have about the study and what is expected of me in the study. I have been assured that all information I give will be kept confidential and that my identity will remain anonymous in any discussion of results or in any written research summary.

I understand that I am free to withdraw from participation in this study at any time without jeopardizing my relationship with Anne Seger or Portland State University.

I have read and understand the foregoing information and agree to participate in this study.

Signature:

Date: 